\title{
An evaluation of a theory based childhood overweight prevention curriculum
}

\author{
Paul Branscum, and Gail Kaye \\ University of Cincinnati \\ Department of Human Nutrition \\ Ohio State University
}

\begin{abstract}
Food Fit, a social cognitive theory based (SCT) nutrition intervention, was implemented to 3rd-5th grade student's at 5 YMCA after-school programs to impact specific dietary behaviors associated with the prevention of childhood overweight $(n=58)$. Pre and post tests were administered for each lesson to evaluate changes in behavioral capabilities (BC), self efficacy (SE), and outcome expectancies (OE) for each lesson's key objectives. A child-modified Food Behavior Checklist was administered before and after the program to evaluate dietary behaviors. Results showed significant improvements for SCT psychosocial variables (i.e. outcome expectancies for eating raw vegetables $(p<0.01)$, self efficacy for eating fruit $(\mathrm{p}<.05))$ Significant dietary changes included an increased consumption of fruits and vegetables as snacks $(p<.001)$, citrus fruits and juice $(p<0.02)$, raw vegetables $(p<.001)$, and increased use of the food label to determine food selection $(\mathrm{p}<0.001)$. The FF program appears to be successful at favorably impacting children's BC, SE and $\mathrm{OE}$ for food selection behaviors thought to contribute to the prevention and treatment of overweight and obesity. FF may be a viable nutrition program for use in multi-component interventions, aimed at impacting behaviors associated with the prevention and treatment of overweight and obesity.
\end{abstract}

(C) 2009 Californian Journal of Health Promotion. All rights reserved.

Keywords: Social Cognitive Theory; Childhood Overweight Prevention

\section{Introduction}

Childhood overweight has tripled in the past thirty years (Ogden, Carroll, Curtin, McDowell, Tabak, \& Flegal, 2006), and is a risk factor for the development of chronic metabolic comorbidities (i.e. type- 2 diabetes, and metabolic syndrome) and psychological conditions (i.e. depression, and social discrimination) (Daniels, et al., 2005). Interventions that can favorably impact health behaviors associated with the prevention of childhood overweight (such as a healthy diet) could potentially prevent unhealthy weight gain among youth, and spare them from the associated metabolic and psychological consequences. However, due to noted limitations, mixed or modest outcomes have been reported for many health-promoting interventions (Thomas, 2006). Two commonly noted limitations include, 1.) The theoretical basis for interventions are rarely described or used to explain results, and 2.) Many interventions have an informative focus, without equipping children with skills and self-efficacy needed to overcome peer and emotional barriers to engage in healthful behaviors (Bandura, 2004; Thomas, 2006).

Food Fit (FF) is a new nutrition intervention, developed by the authors of this article, and was designed to surmount previously noted limitations. Specifically, FF 1) is theoretically based in Social Cognitive Theory (SCT); and 2) attempts to foster the development of selfefficacy through specific program activities. Social cognitive theory posits health behavior change can be mediated by the enhancement of psychosocial variables such as self-efficacy and positive outcome expectancies (Bandura, 2004). 
Therefore, the FF curriculum uses specific pedagogical techniques to enhance children's behavioral capabilities (skills needed to perform a behavior), self-efficacy the confidence to execute skills or behaviors), and positive outcome expectancies (OE) (the value that is placed on the outcome of a behavior) for targeted dietary behaviors. The purpose of this study was to evaluate the impact participation in the FF program has on select SCT psychosocial variables of 3rd-5th grade students and whether these variables impact dietary behaviors.

\section{Methods}

\section{Design}

A convenience sample of children in the 3rd, 4th and 5th grade, from five YMCA sponsored after school programs was used for this study. All sites participated in the intervention for 6 weeks (6 lessons) from April 2007 through May 2007. This study used a treatment only design with children acting as their own control. Approval from the Behavioral and Social Sciences Institutional Review Board, from The Ohio State University, was obtained March 20th, 2007.

\section{Intervention}

Training Plan - Fifty-eight undergraduate students were trained to implement and evaluate FF as a service-learning component of a Community Nutrition course. Students attended weekly training sessions and participated in experiential learning to practice the proper procedures for their assigned task. One-hundred percent of the students attended the training sessions.

Intervention - Food Fit lessons are designed to be "stand-alone" sessions. Six lesson topics included: Choosing lower calorie alternatives for snack foods (Lesson 1), Choosing one serving of a packaged snack food (Lesson 2), Choosing beverages without added sugar (Lesson 3), Choosing cereals with a low amount of added sugar (Lesson 4), Eating fruit and choosing whole fruit for breakfast and snacks (Lesson 5), and Eating vegetables and choosing raw vegetables for a snack (Lesson 6).

Each lesson consisted of five sections: Introduction, Benefits and Consequences, Modeling and Taste Testing, Role-Playing, and Wrap-Up. During the 'Introduction' the instructor introduced and reviewed the lesson's key objectives and defined key terms. In the 'Benefits and Consequences' section, children engaged in hands on activities to demonstrate the positive health benefits and negative consequences associated with the lesson's key objectives. During 'Modeling and Taste Testing', the instructor used positive and vicarious reinforcement to promote the lessons targeted dietary behavior, and children were encouraged to taste-test healthy foods or beverages related to the lesson's key objectives. Next, children participated in structured 'RolePlaying' with the instructor to practice skills learned in the lesson. Finally, during 'Wrap-Up', the instructor reviewed the lesson's key objectives, and children had the opportunity to ask questions about the lesson.

Techniques employed in each lesson were chosen to mediate behavior change by impacting psychosocial variables of SCT, included: (a) hands on activities to teach abstract concepts, (b) discrete skills development through instructor modeling and practice (c) use of positive role models to promote healthy eating behaviors, (d) role playing to practice learned skills and behaviors and to overcome barriers, (e) use of positive and vicarious reinforcement to encourage children to demonstrate targeted behaviors, and (f) taste testing of healthy foods promoted during the lesson.

\section{Outcome Evaluation}

A questionnaire was administered before the intervention to collect children's demographic information. To evaluate dietary behaviors, a child-modified version of the Food Behavior Checklist (CM-FBC) was administered before and after the intervention (Townsend, Kaiser, 
Allen, Joy, \& Murphy, 2003). At the beginning and end of each lesson, a pre and posttest was administered to evaluate psychosocial mediating variables of SCT, including; behavioral capabilities (BC), self-efficacy (SE), and outcome expectancies (OE). BC's were evaluated using skills and knowledge based items. For both SE and $\mathrm{OE}$ a root was used followed by a statement describing a skill or behavior targeted during the lesson. Based on a previously validated tool, the chosen SE root was 'I am sure I can' (Watson, Baronswski, \& Thomspon, 2006). Since no previous research was found for the evaluation of OE's, the root 'I want to' was used. Children responded to these items using three response categories: agree, neutral, or disagree.

\section{Statistical Analysis}

Composite scores were used to evaluate BC's, SE's and OE's. Each lesson used approximately three items to evaluate each variable. For BC's, one point was given for each correct response and no points were given for an incorrect response. For SE's and OE's, two points were given for the response 'Agree', one point was given for the response 'Neutral' and no points were given for the response 'Disagree'. A paired t-test was used to evaluate differences between pre and posttest composite scores per lesson.

Table 1: Pre to Post Changes in Composite Scores for Psychosocial Variables

\begin{tabular}{lcrll}
\hline & $\mathrm{n}$ & PRE & POST & Possi \\
\hline \multicolumn{2}{l}{ Behavioral Capabilities } & (BC) & & \\
Lesson 1 & 45 & 3.45 & 3.61 & $0-5$ \\
Lesson 2 & 41 & 2.29 & $2.9 * * *$ & $0-3$ \\
Lesson 3 & 45 & 3.71 & 4.0 & $0-4$ \\
Lesson 4 & 38 & 4.89 & 4.92 & $0-5$ \\
Lesson 5 & 39 & 1.97 & $2.9 * * *$ & $0-4$ \\
Lesson 6 & 46 & 1.98 & $2.43 * * *$ & $0-3$
\end{tabular}

Example question: How many different vegetables should we eat everyday?

\section{Self Efficacy (SE)}

$\begin{array}{lllll}\text { Lesson 1 } & 45 & 5.2 & 5.57^{* *} & 0-6 \\ \text { Lesson 2 } & 41 & 6.83 & 7.85^{* * *} & 0-8 \\ \text { Lesson 3 } & 45 & 3.49 & 3.71^{* *} & 0-4 \\ \text { Lesson 4 } & 38 & 3.87 & 3.95 & 0-4 \\ \text { Lesson 5 } & 39 & 6.79 & 7.33^{*} & 0-8 \\ \text { Lesson 6 } & 46 & 4.57 & 4.91 & 0-6\end{array}$

Example question: I am sure I can eat a raw vegetable for a snack every day.

\section{Outcome Expectancies (OE)}

$\begin{array}{lllll}\text { Lesson 1 } & 45 & 2.82 & 3.23 & 0-4 \\ \text { Lesson 2 } & 41 & 4.63 & 4.98 & 0-6 \\ \text { Lesson 3 } & 45 & 4.71 & 5.29 * * * & 0-6 \\ \text { Lesson 4 } & 38 & 4.84 & 4.74 & 0-6 \\ \text { Lesson 5 } & 39 & 6.62 & 6.97 & 0-8 \\ \text { Lesson 6 } & 46 & 3.83 & 4.57 * * * & 0-6\end{array}$

Example question: I want to eat raw vegetables for a snack every day.

${ }^{*} p<0.05 . * * p<0.01 . * * * p<0.001$. 
The CM-FBC was also evaluated using a composite score. The composite score was created using items with a forced choice response (yes/no). One point was awarded for each positive response with a maximum possible value of 14 , and higher scores represented more favorable dietary behaviors. Differences between pre and posttest scores were evaluated using a paired t-test. To evaluate the source of variability for this score, each item of the checklist was evaluated using McNemar's test. MINITAB (15.0, State College, PA) and SPSS (16.0, Chicago, IL) were used to perform statistical analysis for outcome measures.

\section{Results}

Fifty-eight children returned parent permission slips, and therefore were enrolled in the study. There were more males $(57 \%)$ than females $(43 \%)$. A majority of the children were in the 3 rd and 4 th grade $(82 \%)$ and either 9 or 10 years old $(76 \%)$. Ethnicities of the children varied from mostly Caucasian (67\%), to African American (19\%) with the remaining children self identified as 'Other' (14\%).

\section{Per Lesson Evaluation}

The participation rate for each lesson were: $78 \%$ Lesson 1 (choosing lower calorie snack foods), $71 \%$ Lesson 2 (choosing one serving of a snack food), 78\% Lesson 3 (choosing beverages without added sugar), 66\% Lesson 4 (choosing cereals with a low amount of added sugar), $67 \%$ Lesson 5 (eating fruit), and 79\% Lesson 6 (eating vegetables). Significant improvements were observed for composite $\mathrm{BC}$ scores in lessons $2 \quad(\mathrm{p}<0.001), 5 \quad(\mathrm{p}<0.001)$, and 6 $(p<0.001)$. Significant improvements were observed for composite SE scores for lessons 1 $(p<0.006), 2(p<0.001), 3(p<0.006)$, and 5 $(\mathrm{p}<0.015)$. Significant improvements were observed for composite $\mathrm{OE}$ scores for lessons 1 $(p<0.01), 3(p<0.001)$, and $6(p<0.001)$. The complete list of composite scores can be found on Table 1.

\section{Dietary Assessment}

Forty-eight children completed the CM-FBC before and after the intervention. Composite CM-FBC scores significantly increased after the intervention $(\mathrm{p}<0.001)$ with the pre-score of 7.2 and the post score of 8.4 (out of 14 total). Significant improvements were also found for four specific self reported behaviors: consuming more fruits and vegetables as snacks $(p<0.001)$, increased consumption of citrus fruits and juice $(p<0.02)$, increased consumption of raw vegetables $(p<0.001)$, and increased use of the food label to determine food selection $(p<0.001)$ (Table 2).

Table 2: Pre and Post Changes for Dietary Behaviors

\begin{tabular}{l} 
Measure $\mathrm{n} \quad$ Pre Score Post Score \\
\hline Composite Score \\
Items with a significant improvement: \\
During the past week did you have citrus fruit or citrus juice?* \\
Do you eat fruit or vegetables as snacks?** \\
During the past week did you have raw vegetables?*** \\
When choosing a food to eat, do you use the Nutrition facts on the food label?** \\
${ }^{*} p<0.05 .{ }^{* *} p<0.01 .{ }^{* * *} p<0.001$.
\end{tabular}

\section{Discussion}

The purpose of this study was to evaluate a single-component nutrition intervention, Food Fit, which attempts to address noted limitations from previous health-promoting intervention studies. Food Fit positively changed variables of SCT, which in turn may have caused favorable changes in dietary behaviors. However, when working with children, it can be difficult to 
expect changes in dietary behaviors, since their parents are the gatekeepers at home, and school administrators are the gatekeepers at schools. That is why this intervention largely targeted snack foods and beverages, two areas for which children can make decisions.

Significant improvements were found for many of the psychosocial variables (BC, SE and $\mathrm{OE}$ ) targeted during the intervention, and changes in these variables appeared to correspond with changes in dietary behaviors. In Lesson 6, children's BC's and OE's significantly improved $(p<0.006)$. These changes corresponded with increases in vegetable consumption at the end of the study; Children reported a significant increase in the consumption of raw vegetables $(p<0.001)$ and fruit and vegetables as snack foods $(p<0.001)$. Similarly, children reported using the Food Label more often to make food selections $(p<0.001)$. This was a learning objective for the first four lessons, and significant improvements were reported for many of these lessons' psychosocial measures (Table 1).

Among the psychosocial variables evaluated in this study, more knowledge and skill-based items (BC) significantly increased compared to $\mathrm{SE}$ and $\mathrm{OE}$ items. This is similar to results reported from two other child-based health promoting interventions 'Gimme 5' (Baronowski, et al., 2000) and 'Pathways'
(Caballero, et al., 2003). It appears BC's may be easier to impact than SE's or OE's given the intervening variables that may have influence, such as the heavy marketing of certain foods (i.e. sugar sweetened beverages), and lack of marketing for other foods (i.e. fruits and vegetables).

This study was designed to be an efficacy study, that is, the intervention was implemented and evaluated under more ideal circumstance. There was approximately a 1:6 teacher/student ratio maintained during each lesson, and there was a separate evaluation staff. The study personnel were also trained weekly, which helped them to stay motivated and recall what lesson activities were to be performed for that week. Whether these results are attainable in other circumstances, and a less intensive training plan, warrants further investigation.

Given this was a preliminary pilot study and due to budgetary and time restraints, there are many limitations to this study to note, including: pre and posttests used for each lesson were not validated measures, a small convenience sample was used, and there was no comparable control group.

\section{Acknowledgments}

This study was supported by a grant from The Columbus Foundation of Columbus, Ohio.

\section{References}

Bandura, A. (2004). Health promotion by social cognitive means. Health Education and Behavior, 31, 143-164.

Baronowski, T., Davis, M., Resnicow, K., Baronowski, J., Doyle, C., Lin, L., et al. (2000). Gimme 5 fruit, juice, and vegetables for fun and health: outcome evaluation. Health Education and Behavior, 27, 96-111.

Baronowski, T., Weber-Cullen, K., \& Baronowski, J. (1999). Psychosocial correlates of dietary intake: advancing dietary intervention. Annual Review of Nutrition, 19, 17-40.

Caballero, B., Clay, T., Davis, S.M., Ethelbah, B., Rock, M.H., Lohman, T., et al. (2003). Pathways: A school based, randomized controlled trial for the prevention of obesity in American Indian schoolchildren. American Journal of Clinical Nutrition, 78, 1030-1038.

Daniels, S.R., Arnett, D.K., Eckel, R.H., Gidding, S.S., Hayman, L.L., Kumanyika, S., et al. (2005). Overweight in children and adolescents: pathophysiology, consequences, prevention, and treatment. Circulation, 111, 1999-2012. 
Lytle, L.A., Nichaman, M.Z., Obarzanek, E., Glovsky, E., Montgomery, D., Nicklas, T, et al. (1993). Validation of 24-hour recalls assisted by food records in third grade children. Journal of the American Dietetic Association, 93, 1431-1436.

Ogden, C.L., Carroll, M.D., Curtin, L.R., McDowell, M.A., Tabak, C.J., \& Flegal, K.M. (2006). Prevalence of overweight and obesity in the United States, 1999-2004. Journal of the American Medical Association, 295, 1549-1555.

Stevens, J,. Taber, D.R., Murray, D.M., \& Ward, D.S. (2007). Advances and controversies in the design of obesity prevention trials. Obesity, $15,2163-2170$.

Thomas, H. (2006). Obesity prevention programs for children and youth: why are their results so modest? Health Education Research, 21, 783-795.

Townsend, M.S., Kaiser, L.L., Allen, L.H., Joy, B., \& Murphy, S.P. (2003). Selecting items for a food behavior checklist for a limited-resource audience. Journal of Nutrition Education and Behavior, $35,69-82$.

Watson, K., Baronswski, T., \& Thomspon, D. (2006). Item response modeling: an evaluation of the children's fruit and vegetable self-efficacy questionnaire. Health Education Research, 21, 147157.

\author{
$\underline{\text { Author Information }}$ \\ Paul Branscum, MS, RD, LD* \\ doctoral student \\ Department of Human Nutrition \\ Ohio State University \\ 3963 Malaer Drive \\ Cincinnati, OH 45241 \\ Phone: (513)-324-9783 \\ Email: branscpw@email.uc.edu \\ Gail Kaye PhD, RD, LD, LPCC \\ Lecturer \\ Department of Human Nutrition \\ Ohio State University \\ 1787 Neil Ave. \\ 347B Campbell Hall \\ Columbus, $\mathrm{OH} 43210$ \\ Phone: (614)-292-5512 \\ Email: gkaye@ehe.osu.edu \\ * corresponding author
}

